\title{
Differences between downscaling with spectral and grid nudging using WRF
}

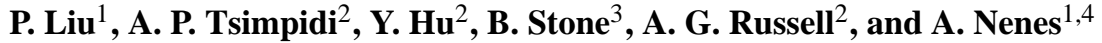 \\ ${ }^{1}$ School of Chemical and Biomolecular Engineering, Georgia Institute of Technology, Atlanta, GA, 30332, USA \\ ${ }^{2}$ School of Civil and Environmental Engineering, Georgia Institute of Technology, Atlanta, GA, 30332, USA \\ ${ }^{3}$ School of Architecture, Georgia Institute of Technology, Atlanta, GA, 30332, USA \\ ${ }^{4}$ School of Earth and Atmospheric Sciences, Georgia Institute of Technology, Atlanta, GA, 30332, USA
}

Correspondence to: A. Nenes (athanasios.nenes@gatech.edu), A. G. Russell (trussell@ce.gatech.edu)

Received: 10 December 2011 - Published in Atmos. Chem. Phys. Discuss.: 12 January 2012

Revised: 1 April 2012 - Accepted: 2 April 2012 - Published: 16 April 2012

\begin{abstract}
Dynamical downscaling has been extensively used to study regional climate forced by large-scale global climate models. During the downscaling process, however, the simulation of regional climate models (RCMs) tends to drift away from the driving fields. Developing a solution that addresses this issue, by retaining the large scale features (from the large-scale fields) and the small-scale features (from the RCMs) has led to the development of "nudging" techniques. Here, we examine the performance of two nudging techniques, grid and spectral nudging, in the downscaling of NCEP/NCAR data with the Weather Research and Forecasting (WRF) Model. The simulations are compared against the results with North America Regional Reanalysis (NARR) data set at different scales of interest using the concept of similarity. We show that with the appropriate choice of wave numbers, spectral nudging outperforms grid nudging in the capacity of balancing the performance of simulation at the large and small scales.
\end{abstract}

\section{Introduction}

Global climate models (GCMs) serve as the primary tool to understand how climate will respond to emission changes (IPCC, 2007). Information on regional scales, however, may be unreliable at scales below $\sim 200 \mathrm{~km}$ (Meehl et al., 2007), which is still too coarse to be directly used in regional climate impact studies (Houghton et al., 2001). Downscaling of global model results has been used to address this issue by bridging the gap of scales between the global and regional climate information. Downscaling can be achieved by statistical methods (called statistical downscaling) or by highresolution regional climate models (RCMs) (called dynamical downscaling).

Dynamical downscaling has been at the forefront of model development of regional climate models (e.g., Dickinson et al., 1989), and now is being used to address how regional air quality would change in future climate. In the process of dynamical downscaling, errors are introduced primarily in two ways. One is due to incomplete model physics. The other type of error results from the downscaling itself. For example, dynamical downscaling typically starts with a set of coarse-resolution large-scale fields, which are used as the initial conditions (ICs) and lateral and surface boundary conditions (LBCs) for the RCMs. As the simulation evolves, the internal solution developed by RCMs may be affected by the size of domain, the spin-up period and update frequency of LBCs. A good summary of such issues are provided by Warner et al. (1997), Giorgi and Mearns (1999) and Denis et al. (2002).

A key source of downscaling errors is the inconsistency along boundaries (Davies, 1976, 1983) since RCM simulation drifts away from the GCMs driving fields. It has been a challenge to balance the performance of RCMs in adding small-scale features and simultaneously retaining the largescale features. Nudging techniques are introduced to RCMs to address this issue. A nudging term is added to the predictive equation of the variable to be nudged in its grid-point model. Davies (1976) introduced the lateral boundary relaxation technique, in which the solution of RCM is nudged to 
the driving field in a "buffer zone" along boundaries. However, this technique is still unable to fulfill the goal of retaining the large-scale information provided by GCMs at the interior of the modeling domain. In order to capture the features of the driving force through the domain, grid nudging (Stauffer and Seaman, 1990) was developed and has been applied to downscaling reanalysis data for regional air quality modeling of historical episodes. In this technique, nudging is conducted in every grid cell. Another nudging technique that has gained interest is spectral nudging (Waldron et al., 1996; von Storch et al., 2000), in which the nudging term is spectrally expanded in both the zonal and meridional directions and only the waves under selected wave numbers are kept in the nudging term. All other waves are filtered out. By keeping the long waves in the nudging term, Miguez-Macho et al. $(2004,2005)$ found that spectral nudging can help eliminate the large-scale precipitation bias, and, at the same time, maintain the features of small scale.

Studies have used dynamical downscaling for the purpose of regional air quality modeling (e.g., Forkel and Knoche, 2006; Gustafson and Leung, 2007; Hogrefe et al., 2004; Leung and Gustafson, 2005; Steiner et al., 2006; Tagaris and Liao, et al., 2008) using boundary (Davies, 1976), grid nudging (Stauffer and Seaman,1990), or no nudging. However, spectral nudging may have an advantage over no nudging or boundary nudging (Feser, 2005; Feser and von Storch, 2005; Rockel et al., 2008; Winterfeldt and Weisse, 2009) and could theoretically outperform grid nudging. From the perspective of spectrum, grid nudging modifies the RCMs results throughout the spectrum with the same strength, however, the short-wave information provided by RCMs is thought to be more reliable than that provided by GCMs. Therefore, grid nudging has the risk of over-forcing the RCMs at small scales (Castro et al., 2005). However, few studies discuss the comparison between grid and spectral nudging and how to determine optimal cut-off wave numbers for spectral nudging.

This study aims at improving the performance of downscaling using spectral nudging with a particular focus on developing regional-scale fields for assessing the impact of climate change on air quality. The main difficulties involve how to evaluate the results between grid and spectral nudging and how to determine the appropriate wave numbers for spectral nudging. In order to address these issues, we focus on the multi-scale performance of downscaling. The applications of scale analysis in the evaluation of downscaling are well summarized by Feser et al. (2011). We use NCEP/NCAR reanalysis data for four historical periods and Weather Research and Forecasting (WRF) Model (Skamarock et al., 2008). The NCEP/NCAR data is used both to provide the information needed for downscaling and to evaluate the downscaling using grid, spectral nudging and no nudging at all.

\section{Method}

The $2.5 \times 2.5$ degree NCEP/NCAR reanalysis data, archived every $6 \mathrm{~h}$, is utilized to drive the WRF (version 3.1.1) downscaling. We compare results developed using grid and spectral nudging for four time episodes: Jul. 2009, Oct. 2009, Jan. 2010 and Apr. 2010. The modeling domain covers the COntiguous United States (CONUS) and portions of southern Canada and northern Mexico, and is centered at $40^{\circ} \mathrm{N}$ and $97^{\circ} \mathrm{W}$ with dimensions of $162 \times 126$ horizontal grids cells with a grid-spacing of $36 \times \mathrm{km}$. It contains 35 vertical levels, with top pressure of $5000 \mathrm{pa}$.

Physical configurations in WRF are kept the same for all simulation considered, except the nudging technique employed. Both grid and spectral nudging are configured to nudge temperature and horizontal winds, but water vapor mixing ratio can only be nudged in grid nudging, and geopotential height only in spectral nudging. Only horizontal winds are nudged at all vertical levels, while no nudging is conducted for other variables within the planetary boundary layer (PBL). The strategy for grid nudging is based on previous studies (Stauffer and Seaman, 1990; Stauffer et al., 1991), which showed that this configuration reduced the bias most. For spectral nudging, same nudging strategy is used within PBL to keep the simulation consistent with grid nudging, and above PBL, geopotential field is nudged, instead of water vapor mixing ratio, which does not have large-scale features as strong as other fields and would not be nudged in the spectral nudging of WRF. The nudging coefficients for all variables for both grid and spectral nudging are set to be $0.0003 \mathrm{~s}^{-1}$ (Stauffer et al., 1995). During the simulation, nudging is conducted every $6 \mathrm{~h}$ consistent with the frequency of the NCEP/NCAR reanalysis data. When spectral nudging is conducted, all waves with wave numbers greater than a preset number are not nudged. In this study, the wave number in both directions is set to be 3 ( $m=n=3$, where $\mathrm{m}$ and $\mathrm{n}$ represent the wave number in zonal and meridional directions, respectively). This preliminary choice is made based on two considerations. One is the scale of the driving field, in which the GCM is able to provide reliable information and this information is also expected to be captured by RCM. von Storch et al. (2000) determined that scales of about $15^{\circ}$ and larger are considered to be reliably analyzed by NCEP. The other consideration is the size of WRF domain. In our study, the WRF domain size is about $6000 \mathrm{~km} \times 4600 \mathrm{~km}$ in zonal and meridional direction respectively. Hence, wave number 3 is employed as the first choice in both directions in order to capture NCEP/NCAR features of scale about $2000 \mathrm{~km}$. Sensitivity tests on cut-off wave number choice are conducted. 


\section{Results}

\subsection{Evaluation methods}

The concept of similarity proposed by von Storch et al. (2000) is used to evaluate the results at different scales, using a metric, $P(t, L)$,

$P(t, L)=1-\frac{\left\langle\left[\psi(t, L)-\psi^{*}(t, L)\right]^{2}\right\rangle}{\left\langle\psi(t, L)^{2}\right\rangle}$

where $t$ is the simulation time, $L$ the scale of interest, $P(t, L)$ the similarity, $\psi(t, L)$ the input field (e.g., the NCEP/NCAR data), $\psi^{*}(t, L)$ the output field (e.g., the WRF output), \langle\rangle the spatial average over the modeling domain. Similarity at different scales of interest is calculated every six hours just after the nudging is updated by calculating the representative values of $\psi(t, L)$ and $\psi^{*}(t, L)$ at different scales. The performance of downscaling at large and small scales is evaluated in the opposite way with respect to similarity using Eq. (1). For large scales, it is better when the downscaling results are more consistent with the input fields, so higher similarities are desired; while for small scales, the results are better when more variance is added, so lower similarities are desired.

The question arises as to how the large and small scales are determined. As mentioned previously, information at about $15^{\circ}$ and larger is considered to be reliably analyzed by NCEP. Accordingly, $2000 \mathrm{~km}$ and larger is chosen as the "large scale". At this scale, when comparing WRF output with NCEP/NCAR input data, the higher the similarity is, the RCM is viewed as performing better. As to the "small scale", instead of the WRF resolution of $36 \mathrm{~km}, 300 \mathrm{~km}$ is chosen in order to capture features that occur at multiple grids, which are more reliably captured by RCMs than individual grid cells. Compared to the NCEP/NCAR data, $300 \mathrm{~km}$ is a small scale and the RCMs should be adding variability that is not resolved by the GCM. Therefore, $300 \mathrm{~km}$ is chosen as the "small scale" and lower similarities are desired.

The calculation of similarity at $2000 \mathrm{~km}$ or $300 \mathrm{~km}$ involves three steps. First, the WRF input field, namely the NCPE/NCAR data, is interpolated to the same resolution as the WRF results. Second, grid cells of $36 \mathrm{~km}$ resolution in the modeling domain are re-divided according to the scale of interest so that each new "aggregated" cell includes multiple original grid cells. For each new cell, its representative values of input and output fields, namely $\psi(t, L)$ and $\psi^{*}(t, L)$ in Eq. (1), are computed from the spatial average of the $36 \mathrm{~km}$ NCEP/NCAR data and WRF results. Finally, similarity is calculated by Eq. (1). At the large-scale case, for instance, the NCEP/NCAR $2.5 \times 2.5$ degree data is first interpolated to a $36 \mathrm{~km}$ resolution, so that for both input and output fields, the modeling domain includes 162 (zonal) by 126 (meridional) cells. Because we are concerned about the features at the scale of about $2000 \mathrm{~km}$, the modeling domain could be re-divided into $3 \times 3$ new cells, each of which has
$54 \times 42$ original cells, and then $\psi(t, L)$ and $\psi^{*}(t, L)$ at the scale of $2000 \mathrm{~km}$ are calculated by averaging the $54 \times 42$ cells of input and output fields respectively.

A critical issue is whether the decrease in similarity at small scales is of reasonable magnitude. In other words, if the current choice of wave numbers insufficiently constrains the RCM so that the similarity decreases too much at the small scale, and vice versa. To answer this question, the $32 \mathrm{~km}$ resolution North America Regional Reanalysis (NARR) data set (Mesinger et al., 2006) is used to assess the appropriate level of similarity decrease between large and small scales. The quality of NARR data has been evaluated with surface station and sounding measurements (Mesinger et al., 2006). In one case, if NARR data set is consistent with NCEP/NCAR data at the large scale, which means similarities between these two data set are high, NARR data set is viewed as the best result we could have after downscaling from NCEP/NCAR data, and the similarity between NCEP/NCAR and NARR data at the small scale could serve as the criteria for a reasonable range of similarity for the small-scale results. If the NARR data set can not provide enough high similarity at the large scale, similarity between NCEP/NCAR and NARR at small scale can not be used directly as the criteria. Instead, the difference of similarity between large and small scale would be used as the reference when assessing whether the change in similarity between input and downscaled fields is reasonable.

\subsection{Similarity at different scales for grid and spectral nudging}

Our ultimate goal is to use the downscaled meteorological fields to drive a regional chemical transport model, we are especially concerned about the fields that will significantly affect the concentration of pollutants. Therefore, we investigate temperature, horizontal kinetic energy (as a surrogate for wind speed), and water vapor mixing ratio; analysis is carried out at three vertical levels, the surface, $850 \mathrm{hpa}$ and $500 \mathrm{hpa}$. Only the results of July 2009 are shown here, since other tested episodes give similar results.

Temperature is nudged when either grid or spectral nudging is applied. At $850 \mathrm{hpa}$, at the large scale, spectral and grid nudging results have high similarities (Fig. 1a) through the simulation period. For example, the temporal means of similarity $P(t, L)$ at the large scale (as summarized in Table 1) is over 0.99999 for both. Hence, the spatial averaged relative difference of temperature is less than $\sqrt{1-P(t, L)} \simeq 0.03$, which means at the large scale, both of the nudging techniques are equally capable of capturing the features of the driving fields. This is not true for small scales, as spectral nudging gives a much lower similarity than grid nudging. Lower similarity is expected at small scales because variance is expected to be added by the RCM. The similarity between the NCEP/NCAR and NARR data (Fig. 1b) is calculated to determine whether or not the lower similarities 
Table 1. Summary of the Mean and Standard Deviation of Similarities for Temperature, Kinetic Energy (KE), Surface Pressure and Water Vapor Mixing Ratio (QV) of July 2009 at Different Scales.

\begin{tabular}{|c|c|c|c|c|c|c|c|c|}
\hline \multirow{2}{*}{ Fields } & \multicolumn{6}{|c|}{ Similarity Between NCEP/NCAP and Downscaling Results by WRF } & \multicolumn{2}{|c|}{$\begin{array}{c}\text { Similarity between } \\
\text { NCEP/NCAR and NARR }\end{array}$} \\
\hline & \multicolumn{2}{|c|}{ Grid Nudging } & \multicolumn{2}{|c|}{ Spectral Nudging } & \multicolumn{2}{|c|}{ No Nudging } & $2000 \mathrm{~km}$ & $300 \mathrm{~km}$ \\
\hline $\mathrm{T}_{s}$ & $\begin{array}{l}0.99999 \\
\pm 0.8 \times 10^{-5}\end{array}$ & $\begin{array}{l}0.99995 \\
\pm 1.6 \times 10^{-5}\end{array}$ & $\begin{array}{l}0.99999 \\
\pm 0.5 \times 10^{-5}\end{array}$ & $\begin{array}{l}0.99995 \\
\pm 1.3 \times 10^{-5}\end{array}$ & $\begin{array}{l}0.99998 \\
\pm 1.0 \times 10^{-5}\end{array}$ & $\begin{array}{l}0.99992 \\
\pm 1.8 \times 10^{-5}\end{array}$ & $\begin{array}{l}0.99998 \\
\pm 1.0 \times 10^{-5}\end{array}$ & $\begin{array}{l}0.99994 \\
\pm 1.9 \times 10^{-5}\end{array}$ \\
\hline $\mathrm{T}_{500}$ & $\begin{array}{l}1.000000 \\
\pm 0.1 \times 10^{-6}\end{array}$ & $\begin{array}{l}0.999999 \\
\pm 0.2 \times 10^{-6}\end{array}$ & $\begin{array}{l}1.000000 \\
\pm 0.1 \times 10^{-6}\end{array}$ & $\begin{array}{l}0.999997 \\
\pm 0.7 \times 10^{-6}\end{array}$ & $\begin{array}{l}0.999990 \\
\pm 4.2 \times 10^{-6}\end{array}$ & $\begin{array}{l}0.999974 \\
\pm 8.1 \times 10^{-6}\end{array}$ & $\begin{array}{l}0.999997 \\
\pm 1.6 \times 10^{-6}\end{array}$ & $\begin{array}{l}0.999991 \\
\pm 2.4 \times 10^{-6}\end{array}$ \\
\hline $\mathrm{KE}_{s}$ & $\begin{array}{l}0.98 \\
\pm 0.9 \times 10^{-2}\end{array}$ & $\begin{array}{l}0.94 \\
\pm 1.7 \times 10^{-2}\end{array}$ & $\begin{array}{l}0.94 \\
\pm 3.4 \times 10^{-2}\end{array}$ & $\begin{array}{l}0.83 \\
\pm 5.8 \times 10^{-2}\end{array}$ & $\begin{array}{l}0.87 \\
\pm 11.7 \times 10^{-2}\end{array}$ & $\begin{array}{l}0.65 \\
\pm 14.3 \times 10^{-2}\end{array}$ & $\begin{array}{l}0.90 \\
\pm 5.3 \times 10^{-2}\end{array}$ & $\begin{array}{l}0.76 \\
\pm 7.8 \times 10^{-2}\end{array}$ \\
\hline $\mathrm{KE}_{850}$ & $\begin{array}{l}1.00 \\
\pm 0.5 \times 10^{-2}\end{array}$ & $\begin{array}{l}0.99 \\
\pm 0.7 \times 10^{-2}\end{array}$ & $\begin{array}{l}0.97 \\
\pm 1.9 \times 10^{-2}\end{array}$ & $\begin{array}{l}0.84 \\
\pm 5.7 \times 10^{-2}\end{array}$ & $\begin{array}{l}0.89 \\
\pm 7.8 \times 10^{-2}\end{array}$ & $\begin{array}{l}0.61 \\
\pm 12.3 \times 10^{-2}\end{array}$ & $\begin{array}{l}0.97 \\
\pm 1.4 \times 10^{-2}\end{array}$ & $\begin{array}{l}0.84 \\
\pm 4.5 \times 10^{-2}\end{array}$ \\
\hline $\mathrm{P}_{s}$ & $\begin{array}{l}0.9999998 \\
\pm 1.7 \times 10^{-7}\end{array}$ & $\begin{array}{l}0.9999994 \\
\pm 2.1 \times 10^{-7}\end{array}$ & $\begin{array}{l}0.9999998 \\
\pm 1.8 \times 10^{-7}\end{array}$ & $\begin{array}{l}0.9999992 \\
\pm 2.4 \times 10^{-7}\end{array}$ & $\begin{array}{l}0.9999973 \\
\pm 2.1 \times 10^{-6}\end{array}$ & $\begin{array}{l}0.9999947 \\
\pm 2.9 \times 10^{-6}\end{array}$ & $\begin{array}{l}0.9999983 \\
\pm 3.8 \times 10^{-7}\end{array}$ & $\begin{array}{l}0.9999913 \\
\pm 6.5 \times 10^{-7}\end{array}$ \\
\hline $\mathrm{QV}_{s}$ & $\begin{array}{l}0.993 \\
\pm 4.3 \times 10^{-3}\end{array}$ & $\begin{array}{l}0.986 \\
\pm 7.3 \times 10^{-3}\end{array}$ & $\begin{array}{l}0.990 \\
\pm 5.4 \times 10^{-3}\end{array}$ & $\begin{array}{l}0.979 \\
\pm 8.8 \times 10^{-3}\end{array}$ & $\begin{array}{l}0.988 \\
\pm 6.5 \times 10^{-3}\end{array}$ & $\begin{array}{l}0.974 \\
\pm 9.8 \times 10^{-3}\end{array}$ & $\begin{array}{l}0.994 \\
\pm 3.5 \times 10^{-3}\end{array}$ & $\begin{array}{l}0.981 \\
\pm 6.9 \times 10^{-3}\end{array}$ \\
\hline $\mathrm{QV}_{850}$ & $\begin{array}{l}0.999 \\
\pm 1.8 \times 10^{-3}\end{array}$ & $\begin{array}{l}0.991 \\
\pm 6.6 \times 10^{-3}\end{array}$ & $\begin{array}{l}0.996 \\
\pm 1.4 \times 10^{-3}\end{array}$ & $\begin{array}{l}0.969 \\
\pm 7.5 \times 10^{-3}\end{array}$ & $\begin{array}{l}0.993 \\
\pm 3.4 \times 10^{-3}\end{array}$ & $\begin{array}{l}0.944 \\
\pm 1.6 \times 10^{-2}\end{array}$ & $\begin{array}{l}0.994 \\
\pm 2.2 \times 10^{-3}\end{array}$ & $\begin{array}{l}0.967 \\
\pm 6.4 \times 10^{-3}\end{array}$ \\
\hline $\mathrm{QV}_{500}$ & $\begin{array}{l}1.000 \\
\pm 0.8 \times 10^{-3}\end{array}$ & $\begin{array}{l}0.996 \\
\pm 3.2 \times 10^{-3}\end{array}$ & $\begin{array}{l}0.970 \\
\pm 1.7 \times 10^{-2}\end{array}$ & $\begin{array}{l}0.880 \\
\pm 2.6 \times 10^{-2}\end{array}$ & $\begin{array}{l}0.970 \\
\pm 1.6 \times 10^{-2}\end{array}$ & $\begin{array}{l}0.817 \\
\pm 4.9 \times 10^{-2}\end{array}$ & $\begin{array}{l}0.992 \\
\pm 4.6 \times 10^{-3}\end{array}$ & $\begin{array}{l}0.950 \\
\pm 1.4 \times 10^{-2}\end{array}$ \\
\hline
\end{tabular}

Subscripts s, 850 and 500 stand for surface, 850 hpa and 500 hpa.

Table 2. Summary of the Mean and Standard Deviation (SD) of the Distribution of Temperature. Difference at 500 hpa of July 2009 at Different Scales.

\begin{tabular}{|c|c|c|c|c|}
\hline \multirow[t]{2}{*}{ Data set } & \multicolumn{2}{|c|}{ at the Scale of $2000 \mathrm{~km}$} & \multicolumn{2}{|c|}{ at the Scale of $300 \mathrm{~km}$} \\
\hline & Mean $(\mathrm{K})$ & $\mathrm{SD}(\mathrm{K})$ & Mean $(\mathrm{K})$ & $\mathrm{SD}(\mathrm{K})$ \\
\hline NARR minus NCEP/NCAR & -0.11 & 0.533 & -0.10 & 1.219 \\
\hline Grid Nudging minus NCEP/NCAR & -0.09 & 0.173 & -0.09 & 0.337 \\
\hline Spectral Nudging minus NCEP/NCAR & -0.08 & 0.209 & -0.07 & 0.837 \\
\hline
\end{tabular}

given by nudging techniques at the small scale are consistent with using NARR data. The decrease in similarity for NCEP/NCAR and NARR data between large and small scale indicates that at the small scale, spectral nudging performs better than grid nudging because of a lower similarity. If nudging is not applied during the simulation, the RCM is not able to retain the features at large scales (Table 1 ). The results at $500 \mathrm{hpa}$ are very similar to the results at $850 \mathrm{hpa}$ (Table 1), except that the difference of similarity between grid and spectral nudging is even smaller. At the small scale, for instance, the difference of the mean between the two nudging techniques is on the order of $10^{-6}$, and the difference of standard deviation of similarity on the order of $10^{-7}$. We have to ask, does the small difference in similarity really matter? In other words, we want to know if the similarity is still able to be used to assess the performance of downscaling, or it is just noise when the difference of similarity is very small. To answer this question, we compare the probability distribution of the temperature difference between the NCEP/NCAR data and the WRF output (by grid and spectral nudging respectively) with the distribution of temperature difference between NCEP/NCAR data and NARR data (Table 2). Changing from the large to small scale, the width of the distribution provided by grid nudging changes little compared with spectral nudging and NARR data. This indicates that for the temperature field at $500 \mathrm{hpa}$, grid nudging over-forces the 

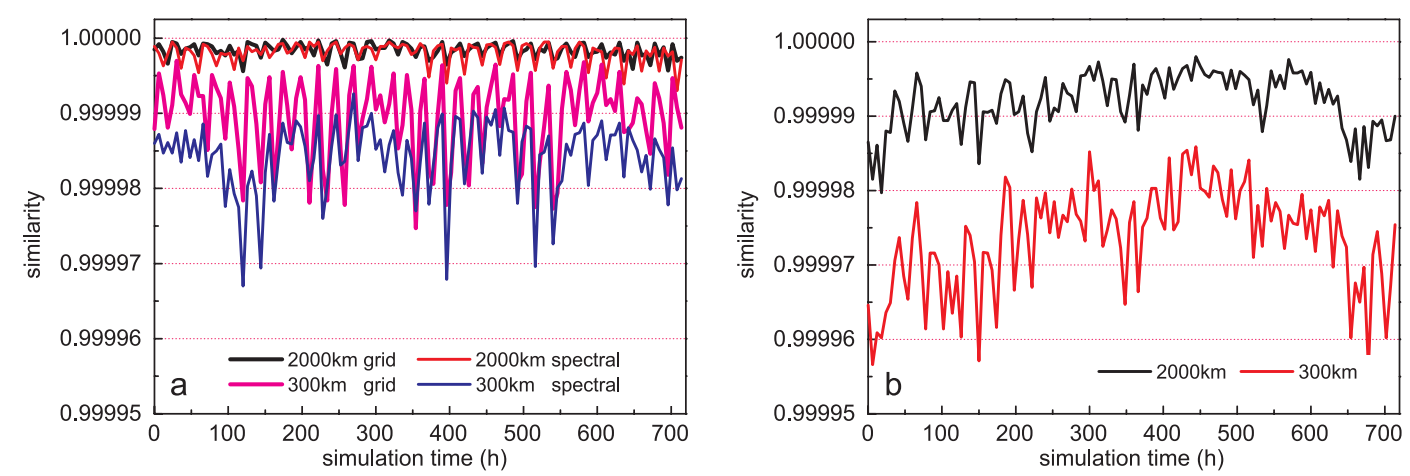

Fig. 1. Time series plots of similarity for temperature at $850 \mathrm{hpa}, 2000 \mathrm{~km}$ and $300 \mathrm{~km}$ scales for July 2009 . (a) similarity between NCEP/NCAP and downscaling results by WRF by grid and spectral nudging; (b) similarity between NCEP/NCAR and NARR data.
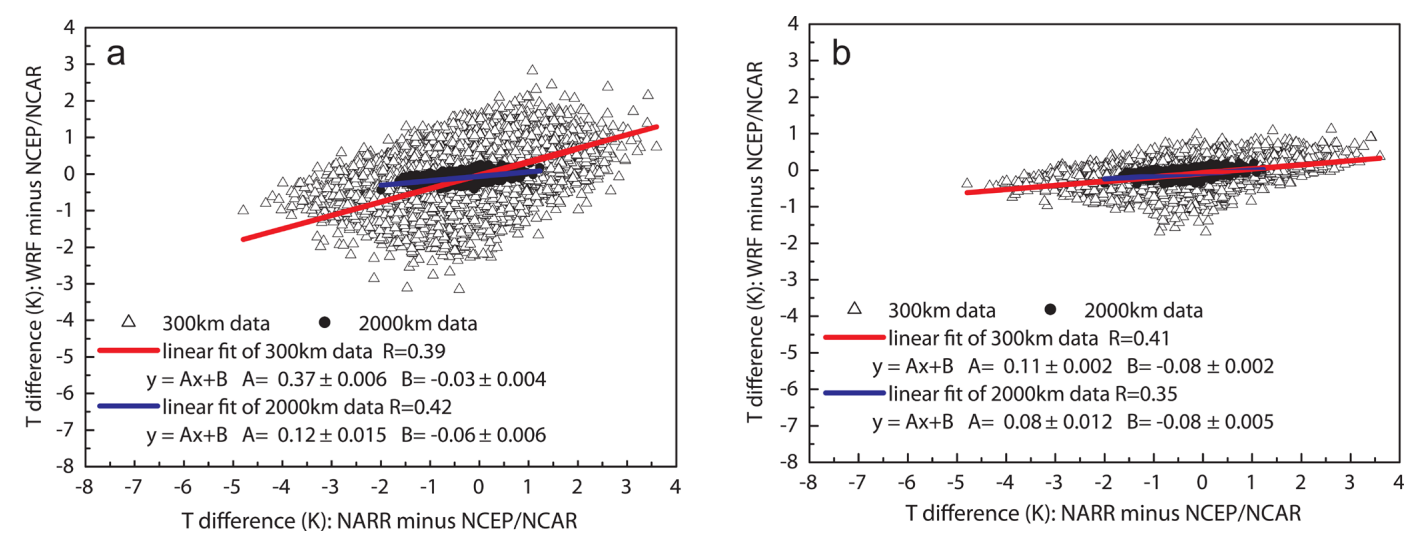

Fig. 2. Correlation for the temperature anomaly from NCEP/NCAR data at $500 \mathrm{hpa}, 2000 \mathrm{~km}$ and $300 \mathrm{~km}$ scales for July 2009 with linear regression of $95 \%$ confidence. (a) anomaly of WRF output by spectral nudging vs. anomaly of NARR data; (b) anomaly of WRF output by grid nudging vs anomaly of NARR data.

RCM results towards the driving fields and the small-scale features expected from RCM are hindered. To further investigate whether the larger variance provided by spectral nudging is reasonable or not, the correlation between WRF output and NARR data is investigated by orthogonal regression (Fig. 2). At the small scale, spectral nudging improves the correlation with NARR data compared with grid nudging by giving a slope more close to 1 . Other regression methods, such as least square regression, are also tested and we get consistent results. The results above indicate that the metric of similarity at different scales is important in evaluating the performance of downscaling, even when the difference between similarity values is very small. At the surface, grid and spectral nudging show little difference in similarity, which is not unexpected because temperature is not nudged within the PBL.

Spectral nudging, likewise, performs better than grid nudging for horizontal kinetic energy (KE) with comparable similarity at the large scale and lower similarity consistent with NARR at the small scale at both 850 hpa (Fig. 3) and and $500 \mathrm{hpa}$ (Table 1). The improvement in the decrease of similarity implies significant differences of the nudged vari- able between grid and spectral nudging. For example, at $500 \mathrm{hpa}$ (Table 1), grid nudging leads to a mean KE similarity of 0.997 at the small scale; while spectral nudging decreases the mean of similarity to 0.940 . The kinetic energy difference between grid and spectral nudging is around $20 \%$. In addition, at the small scale, the similarity found using spectral nudging varies temporally with the same trend as that of NCEP/NCAR and NARR data (Fig. 3), However, the similarity found using grid nudging shows little such variability. The variance of similarity (Table 1) also indicates that at small scale, spectral nudging performs better than grid nudging in the magnitude of variability. If no nudging is used, the results not only have low similarities at different scales, but also give much larger variance compared with NARR data (Table 1).The results at the surface are similar to those at 500 hpa and 850 hpa (Table 1 ).

Different similarities for KE suggest that the results from grid and spectral nudging can be very different for fields strongly affected by KE, such as clouds and precipitation, both of which are important in regional climate and air quality modeling. Cloud hydrometeor mixing ratios provided by WRF are used to calculate the monthly averaged cloud mass 

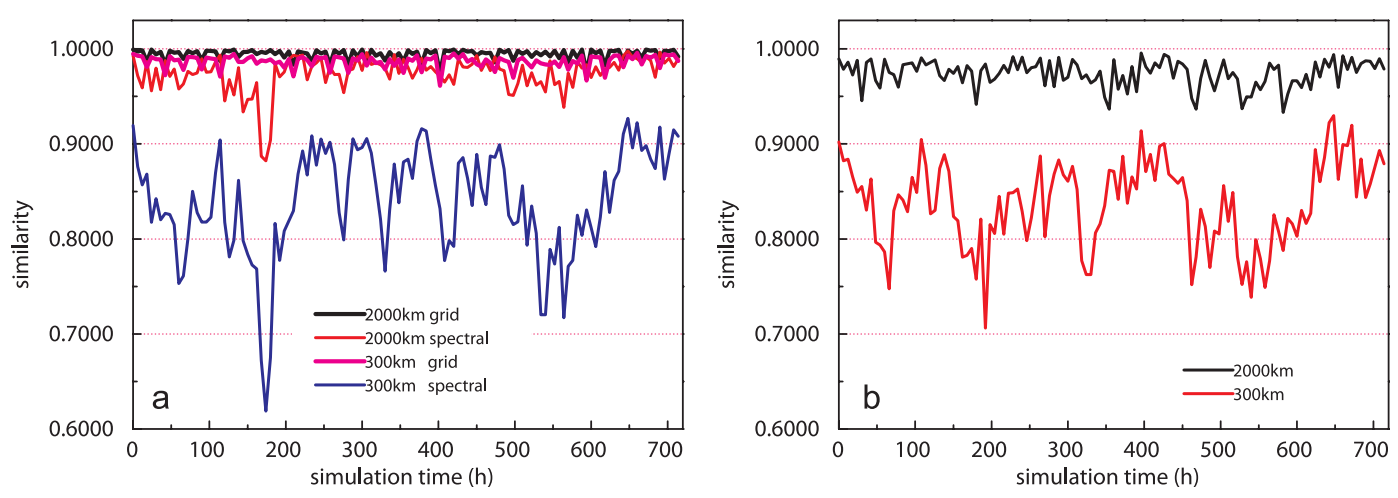

Fig. 3. Time series plots of similarity for horizontal kinetic energy at $850 \mathrm{hpa}, 2000 \mathrm{~km}$ and $300 \mathrm{~km}$ scales for July 2009 . (a) similarity between NCEP/NCAP and downscaling results by WRF by grid and spectral nudging; (b) similarity between NCEP/NCAR and NARR data.

(including cloud water, cloud rain, ice, snow and graup) in each column and compared with the convective cloud fraction averaged from NARR data archived every 3 hours. The convective cloud from NARR data is used for comparison instead of total cloud because the horizontal resolution of WRF in this study is not high enough to explicitly resolve such clouds. The two nudging techniques lead to greater differences over the middle and the eastern regions of the US, with spectral nudging better capturing the cloud features (Fig. 4). The superiority of spectral nudging becomes more apparent when comparing the precipitation with NARR data (Fig. 4b). Grid nudging significantly depresses the precipitation across the middle of the US. Moreover, in the southeast, results from spectral nudging more closely resemble NARR data than grid nudging. Spectral nudging (Fig. 4d) generates the similar rainfall region over the east coast, although the rainfall region shifted toward southwest compared with NARR data; grid nudging (Fig. 4f) did not generate this feature at all. The difference in precipitation shown above includes the impact of nudging horizontal KE and water vapor mixing ratio as well. To exclude the impact of the latter, we also test the case by grid nudging with the same configuration in Sect. 2, except that we turn off the nudging of water vapor mixing ratio (this case is referred as "grid no gq" and the cases with nudging configuration described in Sect. 2 are referred as "grid" and "spectral" respectively). Compared with "grid" case, "grid no gq" case shows little difference in the similarities of temperature and horizontal KE at both large and small scales (not shown here). Therefore, the difference of precipitation between "grid no gq" and "spectral" cases better represents the impact of horizontal KE. We find out that compared with "spectral" case, "grid no gq" case (Fig. 4h) reproduces precipitation regions over Canada and the Atlantic Ocean, although with less strength. However, it still fails to generate the features across the middle of the US. In addition, much more rainfall occurs over the Gulf of Mexico.

Another field closely affected by KE is surface pressure. Similarities of surface pressure at different scales are calcu- lated and compared with the similarities of NARR data (Table 1), with little difference in the mean and standard deviation of similarity between grid and spectral nudging. The spatially averaged change in surface pressure is on the order of $10 \mathrm{~Pa}$ between the large and small scales (Eq. 1). However, the similarity between NCEP/NCAR and NARR data shows that the change in surface pressure is of magnitude of $100 \mathrm{~Pa}$ between the large and small scales. Therefore, nudging does not impact the surface pressure significantly, although spectral nudging improves the simulated $\mathrm{KE}$ at the small scale.

Grid nudging, not spectral nudging, is applied to water vapor mixing ratio in the "grid" case of this study. If spectral nudging is used, the correction to water vapor mixing ratio results from the changes in other fields. At the large scale, the similarity using spectral nudging is still as high as that by grid nudging at the surface and $850 \mathrm{hpa}$ (Table 1). At $500 \mathrm{hpa}$, however, spectral nudging does not maintain the large-scale features as well as grid nudging (Fig. 5a), although the similarity of grid and spectral nudging at $500 \mathrm{hpa}$ differs little for temperature and horizontal kinetic energy. This can be linked to the prediction of cloud formation, which is at a scale smaller than that is captured by the GCM, and is very sensitive to a number of local factors. At the small scale, for all the vertical layers of interest, spectral nudging provides the desired decrease in similarity of water vapor mixing ratio as compared to NARR; while for grid nudging, little difference occurs at small and large scales (Table 1).

\subsection{Sensitivity to wave numbers in spectral nudging}

Choice of wave numbers in spectral nudging impacts the quality of downscaling. If the wave number is too large, which means the nudging term includes all the longer waves under the selected wave numbers, the results of spectral nudging would approach grid nudging, because the results are overly forced at the smaller scale. If the wave number is too small, the long waves included in the nudging term may not be able to represent enough energy to force the RCMs to replicate the large scale features. Here, we 

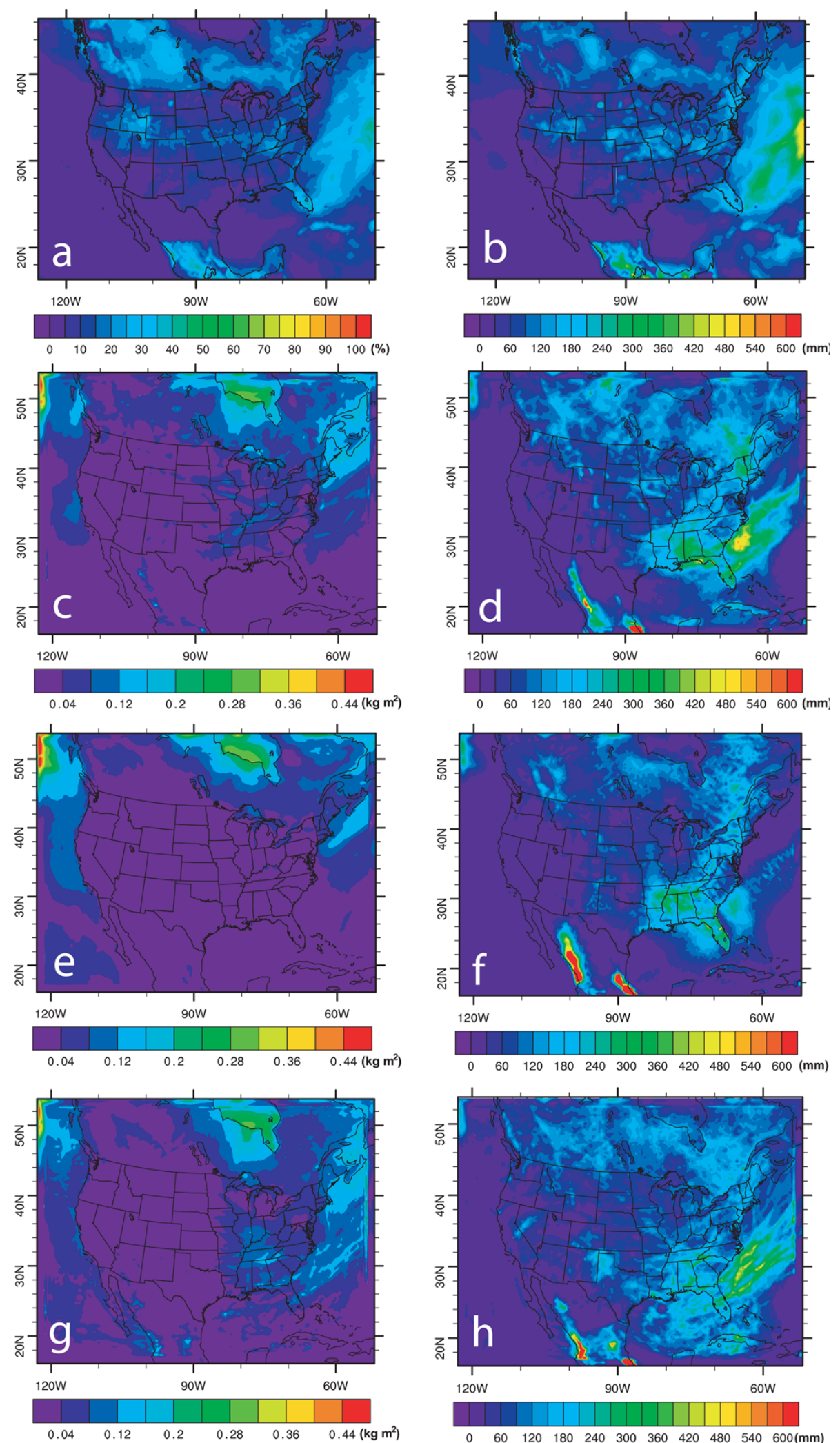

Fig. 4. Comparison of monthly averaged cloud fraction (or cloud water) and monthly accumulated precipitation using WRF and NARR data for July 2009. (a), (b) NARR; (c), (d) WRF simulation using spectral nudging; (e), (f) WRF simulation using grid nudging; (g), (h) WRF simulation using "grid no gq". 

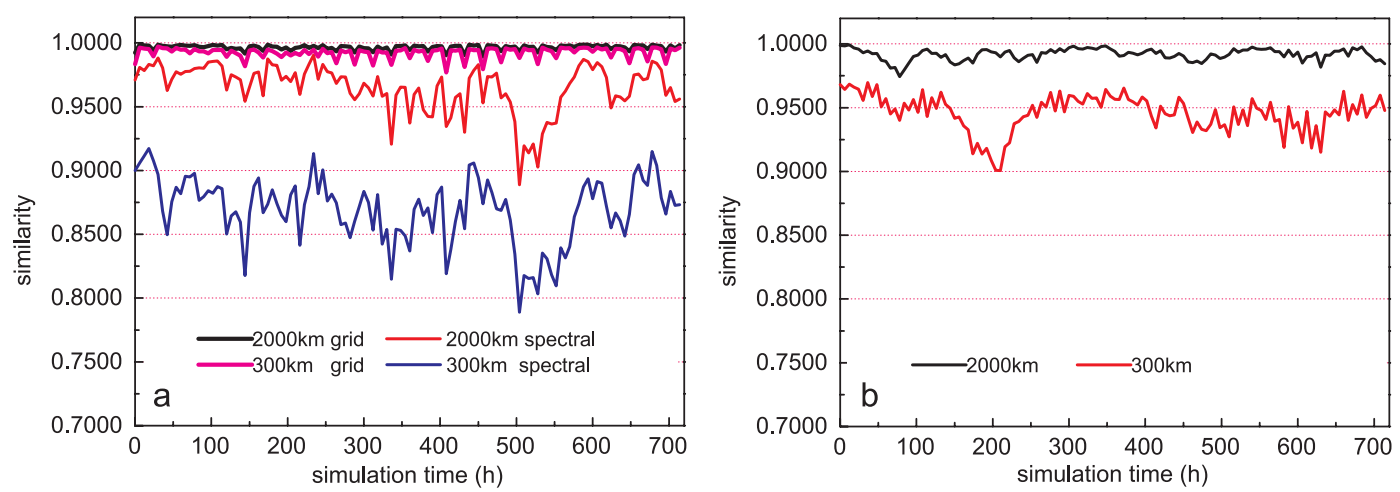

Fig. 5. Time series plots of similarity for water vapor mixing ratio at $500 \mathrm{hpa}, 2000 \mathrm{~km}$ and $300 \mathrm{~km}$ scales for July 2009 . (a) similarity between NCEP/NCAP and downscaling results by WRF by grid and spectral nudging; (b) similarity between NCEP/NCAR and NARR data set.
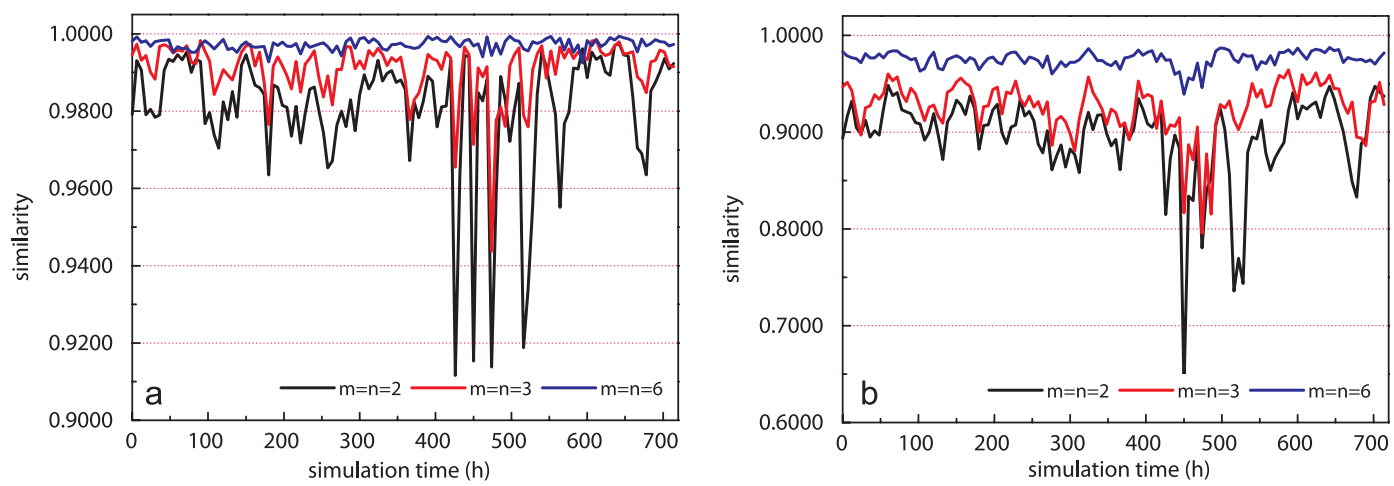

Fig. 6. Time series plots of similarity of horizontal kinetic energy at 850 hpa for January 2010 by spectral nudging with different wave numbers. (a) similarity between NCEP/NCAP and downscaling results by WRF at $2000 \mathrm{~km}$ scale; (b) similarity results at $300 \mathrm{~km}$ scale.

Table 3. Summary of the Temporal Mean and Standard Deviation (SD) of the Similarity of Horizontal Kinetic Energy at $850 \mathrm{hpa}$ of January 2010 at Different Scales.

\begin{tabular}{lccccc}
\hline wave number & \multicolumn{2}{c}{ at the Scale of $2000 \mathrm{~km}$} & & \multicolumn{2}{c}{ at the Scale of $300 \mathrm{~km}$} \\
\hline & Mean & SD & & Mean & SD \\
\cline { 2 - 3 } \cline { 5 - 6 }$m=n=2$ & 0.98 & $1.6 \times 10^{-2}$ & & 0.90 & $4.5 \times 10^{-2}$ \\
$m=n=3$ & 0.99 & $0.7 \times 10^{-2}$ & & 0.93 & $2.8 \times 10^{-2}$ \\
$m=n=6$ & 1.00 & $0.1 \times 10^{-2}$ & & 0.98 & $0.8 \times 10^{-2}$ \\
\hline
\end{tabular}

conduct a sensitivity test to investigate how the fields of interest respond to changes in wave numbers.

In our initial tests, the wave numbers for spectral nudging were 3 in both zonal and meridional directions. Here, wave number sets of $m=n=2$ and $m=n=6$ are tested as applied to the four episodes simulated and the similarity at the large and small scales are investigated. For the horizontal kinetic energy, at both large and small scales (Fig. 6), when the wave numbers decrease, the ability of spectral nudging to follow large scale features becomes weaker as the similarity markedly decreases; while when wave numbers increase, the performance of spectral nudging approaches grid nudging by giving high similarity values, particularly at the small scale. As the wave numbers increase, the variability and difference between large and small scales becomes smaller (Table 3). It is critical to choose the wave numbers which are able to generate reasonable difference between different scales and variability at the scales of interest. Therefore, the results summarized in Table 1 indicate the choice of wave numbers $m=n=3$ is an appropriate choice for the studied case here. The results of sensitivity test also suggest that similarity at the small scale is more sensitive to wave number choice than that at the large scale (Table 3). As wave number increase, the loss of variability at small scales is larger than the increase of consistency at large scales. Therefore, smaller wave numbers are preferred as long as the features at the large scales of interest can be captured, in order to reduce the loss of variability at small scales. The choice of wave number had little impact on temperature and water vapor. 


\section{Conclusions}

The performance of two nudging techniques, grid and spectral nudging are examined in the downscaling of NCEP/NCAR data with the Weather Research and Forecasting (WRF) Model. The simulations are compared against the results with North America Regional Reanalysis (NARR) data set at different scales of interest using the concept of similarity.

Compared with grid nudging, spectral nudging provides a better balance between the need to keep RCM results consistent with the large scale driving forces that would be provided by GCMs, and at the same time, allows more variance added at the smaller scales. The performance of spectral nudging is very good for temperature and horizontal kinetic energy at $850 \mathrm{hpa}$ and $500 \mathrm{hpa}$. In addition, the improvement at the small scale allowed by spectral nudging is not only reflected in spatial variability, but temporal variability as well.

In order to take the advantage of spectral nudging, appropriate wave numbers should be chosen based on a thorough sensitivity analysis. The results of sensitivity tests show that for the case studied here, the choice of wave numbers set at $m=n=3$, or wave lengths of about $2000 \mathrm{~km}$ is well supported. The choice of wave numbers is determined by the size of modeling domain and the scale of driving forces that RCMs should retain. Results suggest that the similarity at the small scale is more sensitive to wave numbers than that at the large scale, and as wave numbers increase, spectral nudging performs more similarly to grid nudging and begins to overforce the RCMs results at the small scale. The sensitivity tests also imply that many of the biases of large-scale modes are associated with resolved small-scale features, and only spectral nudging can help to alleviate the biases while keeping the resolved small-scale features to a reasonable extent. In addition, much of the small scale variability may not have a significant impact on large scale features

Acknowledgements. This research was made possible by grants from the US Environmental Protection Agency (EPA) through grant \#834281 and the Centers for Disease Control CDC through grant \#5U01EH000432-02. Although the research described in the article has been funded wholly or in part by the U.S. EPA and the $\mathrm{CDC}$, it has not been subjected to any EPA or CDC review and therefore does not necessarily reflect the views of the Agency or Center, and no official endorsement should be inferred.

Edited by: J. H. Seinfeld

\section{References}

Anthes, R. A.: Regional models of the atmosphere in middle latitudes, Mon. Weather. Rev., 111, 1306-1335, 1983.

Castro, C. L., Pielke Sr., R. A., and Leoncini, G.: Dynamical downscaling: Assessment of value retained and added using the Regional Atmospheric Modeling System (RAMS), J. Geophys. Res., 110, D05108, doi:10.1029/2004JD004721, 2005.
Davies, H. C.: A lateral boundary formulation for multi-level prediction models, Q. J. Roy. Meteor. Soc., 102, 405-418, 1976.

Davies, H. C.: Limitations of some common lateral boundary schemes used in regional NWP models, Mon. Weather Rev., 111, 1002-1012, 1983.

Denis, B., Laprise, J., Caya, D., and Côté, J.: Downscaling ability of one-way nested regional models: The big-brother experiment, Clim. Dynam., 18, 627-646, 2002.

Dickinson, R. E., Errico, R. M., Giorgi, F., and Bates, G. T.: A regional climate model for the western United States, Clim. Change, 15, 383-422, 1989.

Feser, F.: Enhanced detectability of added value in limited area model results separated into different spatial scales, Mon. Weather Rev., 134, 2180-2190, 2006.

Feser, F. and von Storch, H.: A spatial two-dimensional discrete filter for limited area model evaluation purposes, Mon. Weather Rev., 133, 1774-1786, 2005.

Feser, F., Rockel, B., von Storch, H., Winterfeldt, J., and Zahn, M.: Regional climate models add value, B. Am. Meteor. Soc., 92, 1181-1192, 2011.

Forkel, R. and Knoche R.: Regional climate change and its impact on photooxidant concentrations in southern Germany: Simulation with a coupled regional climate-chemistry model, J. Geophys. Res., 111, D12302, doi:10.1029/2005JD006748, 2006.

Giorgi, F. and Mearns, L. O.: Introduction to special section: regional climate modeling revisited, J. Geophys. Res., 104, doi:10.1029/98JD02072, 6335-6352, 1999.

Gustafson, W. I. and Leung, L. R.: Regonal downscaling for air quality assessment, A reasonable proposition?, Am. Meteorol. Soc., 1215-1227, 2007.

Hogrefe, C., Lynn, B., Civerolo, K., Ku, J. Y., Rosenthal, J., Rosenzweig, C., Goldberg, R., Gaffin, S., Knowlton, K., and Kinney, P. L.: Simulation changes in regional air pollution over the eastern United States due to changes in global and regional climate and emissions, J. Geophys. Res., 109, D22301, doi:10.1029/2004JD004690, 2004.

Houghton, J. T., and Ding, Y., Griggs, D. J., Noguer, M., van der Linden, P. J., Dai, X., Maskell, K., and Johnson, C. A.: Climate Change 2001: the Science Basis, Cambridge Univ. Press, Cambridge, UK, 944 pp., 2001.

IPCC: Climate Change 2007: The physical science basis, in Contribution of the Working Group I to the Fourth Assessment Report of the Intergovernmental Panel on Climate Change, edited by: Solomon, S., Qin, D., Manning, M., Chen, Z., Marquis, M., Averyt, K. B., Tignor, M., and Miller, H. L., Cambridge University Press, Cambridge, UK, 2007.

Leung, L. R. and Gustafson, W. I.: Potential regional climate change and implications to US air quality, Geophys. Res. Lett., 32, L16711, doi:10.1029/2005GL022911, 2005.

Meehl, G. A., Stocker, T. F., Collins, W. D., Friedlingstein, P., Gaye, A. T., Gregory, J. M., Kitoh, A., Knutti, R., Murphy, J. M., Noda, A., Raper, S. C. B., Watterson, I. G., Weaver, A. J., and Zhao, Z. C.: Global climate projections, in Climate Change 2007: The Physical Science Basis - Contribution of Working Group to the Fourth Assessment Report of the Inter-governmental Panel on Climate Change, Cambridge Univ. Press, Cambridge, UK, 747845, 2007.

Mesinger, F., DiMego, G., Kalnay, E., Mitchell, K., Shafran, P. C., Ebisuzaki, W., Jovic, D., Woollen, J., Rogers, E., Berbery, E. H., 
Ek, M. B., Fan, Y., Grumbine, R., Higgins, W., Li, H., Lin, Y., Manikin, G., Parrish, D., and Shi, W.: North American regional reanalysis, Bull. Am. Meteorol. Soc., 87, 343-360, 2006.

Miguez-Macho, G.: Spectral nudging to eliminate the effects of domain position and geometry in regional climate model simulations, J. Geophys. Res.-Atmos., 109, D13104, doi:10.1029/2003JD004495, 2004.

Miguez-Macho, G.: Regional climate simulations over North America: Interaction of local processes with improved largescale flow, J. Climate, 18, 1227-1246, 2005.

Noguer, M., Jones, R., and Murphy, J.: Sources of systematic errors in the climatology of a regional climate model over Europe, Clim. Dynam., 14, 691-712, 1998.

Rockel, B., Castro, C. L., Pielke Sr., R. A., von Storch, H., and Leoncini, G.: Dynamical downscaling: Assessment of model system dependent retained and added variability for two different regional climate models, J. Geophys. Res., 113, D21107, doi:10.1029/2007JD009461, 2008.

Seaman, N. L., Stauffer, D. R., and Lario-Gibbs, A. M.: A multiscale four-dimensional data assimilation system applied in the San Joaquin valley during SARMAP: Part I: Modeling design and basic performance characteristics, J. Appl. Meteor., 34, 1739-1761, 1995.

Skamarock, W. C., Klemp, J., Dudhia, J., Gill, D. O., Barker, D. M., Duda, M. G., Huang, X. Y., Wang, W., and Powers, J. G.: A Description of the Advanced Research WRF Version 3, NCAR Technical note NCARTN-475+STR, 2008.

Staniforth, A.: Regional modeling: A theoretical discussion, Meteor. Atmos. Phys., 63,15-29, 1997.

Stauffer, D. R. and Seaman, N. L.: Use of four-dimensional data assimilation in a limited-area mesoscale model, Part I: Experiments with synoptic-scale data, Mon. Weather Rev., 118, 1250-1277, 1990.
Stauffer, D. R., Seaman, N. L., and Binkowski, F. S.: Use of fourdimensional data assimilation in a limited-area mesoscale model: Part II: effects of data assimilation within the planetary boundary layer, Mon. Wea. Rev., 119, 734-754, 1991.

Steiner, A. L., Tonse, S., Cohen, R. C., Goldstein, A. H., and Harley, R. A.: Influence of future climate and emissions on regional air quality in California, Geophys. Res., 111, D18303, doi:10.1029/2005JD006935, 2006.

Tagaris, E., Liao, K.-J., Manomaiphiboon, K., He, S., Woo, J.-H., Amar, P., and Russell, A. G.: The role of climate and emission changes in future air quality over southern Canada and northern Mexico, Atmos. Chem. Phys., 8, 3973-3983, doi:10.5194/acp-83973-2008, 2008.

von Storch, H., Langenberg, H., and Feser, F.: A spectral nudging technique for dynamical downscaling purposes, Mon. Weather. Rev., 128, 3664-3673, 2000.

Waldron, K. M., Paegle, J., and Horel, J. D.: Sensitivity of a spectrally filtered and nudged limited-area model to outer model options, Mon. Weather Rev., 124, 529-547, 1996.

Warner, T. T., Peterson, R. A., and Treadon, R. E.: A tutorial on lateral boundary conditions as a basic and potential serious limitation to regional numerical weather prediction, B. Am. Meteor. Soc., 78, 2599-2617, 1997.

Winterfeldt, J. and Weisse, R.: Assessment of value added for surface marine wind speed obtained from two regional climate models, Mon. Weather Rev., 137, 2955-2965, 2009. 